\title{
ASSESSMENT OF THE IMPACT OF WHIRLPOOL BATHS ON CHANGE VASCULAR PERFUSION WITHIN THE LOWER LIMBS IN PATIENTS WITH CHRONIC LOWER LIMB ISCHAEMIA
}

\author{
Kapusta Joanna ${ }^{1}$, Kowalski Jan¹, Pawlicki Lucjan¹, Irzmański Robert' ${ }^{1}$
}

\section{${ }^{1}$ Clinic of Internal Medicine and Cardiac Rehabilitation; Medical University Of Lodz - Lodz, Poland}

Introduction: The incidence of atherosclerotic occlusive arterial disease increases with age. Due to the large number of patients affected by this problem, and the chronic nature of the disease they are being sought various treatments. Whirlpool baths is one of the procedures recommended in order to improve peripheral circulation of the lower limbs.

Purpose: An attempt to answer the question- is whirlpool baths influence change of vascular perfusion within the legs of patients with chronic lower limb ischaemia?

Method: The study involved 35 patients with chronic lower limb ischaemia, in stage I and II of the Fontaine classification, including males and females, aged $37-82$ years, admitted to the Clinic of Internal Medicine and Cardiac Rehabilitation in Lodz. Patients were divided into two groups. Patients from group 1 were performed a series of 12 whirlpool baths of the lower limbs, every second day, in a sitting position, in water at a temperature of $35-40^{\circ} \mathrm{C}$, for about 20 minutes and individually selected training includes respiratory exercises and free active exercises of lower limbs, such as calf raises, plantar and dorsiflexion exercises, every second day, for $30 \mathrm{~min}$. Patients from group 2 were performed only individually selected training includes respiratory exercises and free active exercises of lower limbs, every second day, for $30 \mathrm{~min}$. To assess the impact of whirlpool baths in patients surveyed impedance plethysmography and a 6 minute walk test was performed.
Results: Increase of vascular perfusion within the lower limbs and the distance in the 6 MWT.

Disscussion and Conclusion: Treatment of patients with peripheral circulatory disorders should lead to the elimination of symptoms of limb ischemia, inhibiting the progress of vascular lesions. Nowadays, a bath is not only a simple hygienic procedure. Appropriately matched perfectly affects the body, it nourishes and strengthens. Because it is known for the wide impact of hydrotherapy treatments in this study was designed to assess the impact of whirlpool massage to change on selected parameters of the cardiovascular system of patients with PAD. The results indicate that the whirlpool baths impact on the improvement of lower limb blood flow.

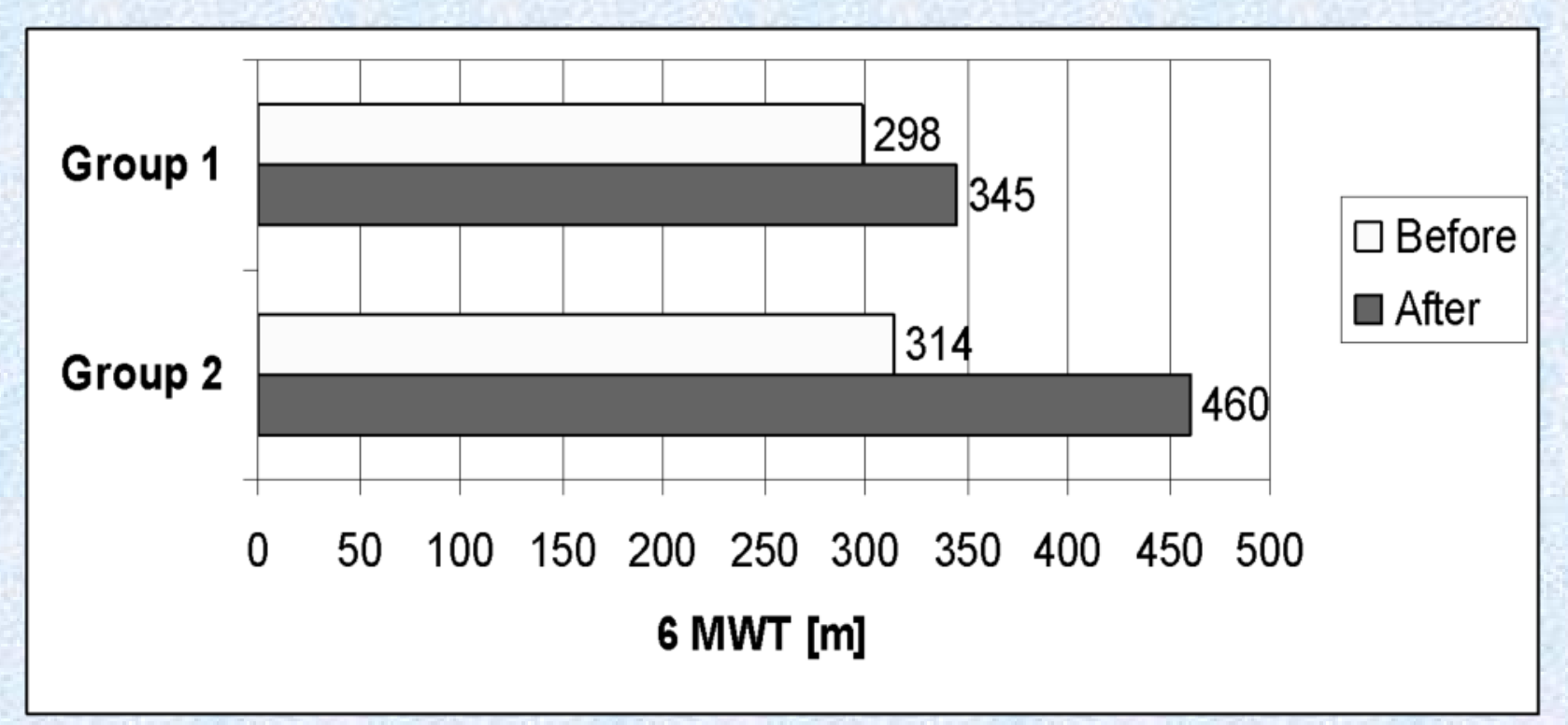

Figure 1. Arrangement of the value - 6MWT depending on the research group $(1,2)$

Table 1. Arrangement of the value plethysmography parameters: Pampl [\%o], PSlope [\%o/sek], CT [ms], PT [ms] depending on the research group

\begin{tabular}{|c|c|c|c|c|c|c|c|c|c|c|c|}
\hline \multirow[b]{2}{*}{ Parameters } & \multirow[b]{2}{*}{ Group } & \multirow[b]{2}{*}{$\begin{array}{l}\text { Measurement } \\
\text { point }\end{array}$} & \multicolumn{7}{|c|}{ Descriptive statistics } & \multirow{2}{*}{\multicolumn{2}{|c|}{$\begin{array}{c}\text { Wilcoxon } \\
\text { test }\end{array}$}} \\
\hline & & & Average & $\begin{array}{l}\text { Standard } \\
\text { deviation }\end{array}$ & Minimum & $\begin{array}{l}\text { The lower } \\
\text { quartile }\end{array}$ & Median & $\begin{array}{l}\text { The upper } \\
\text { quartile }\end{array}$ & Max. & & \\
\hline \multirow{4}{*}{$\frac{\bar{a}}{\frac{\bar{a}}{a}}$} & Group 1 & \multirow{2}{*}{ Before } & 0,51 & 0,07 & 0,30 & 0,39 & 0,53 & 0,60 & 0,71 & Group 1 & 0,4026 \\
\hline & Group 2 & & 0,34 & 0,09 & 0,11 & 0,26 & 0,37 & 0,43 & 0,54 & \multirow{3}{*}{ Group 2} & \multirow{3}{*}{0,2256} \\
\hline & Group 1 & \multirow{2}{*}{ After } & 0,53 & 0,11 & 0,30 & 0,40 & 0,52 & 0,71 & 0,78 & & \\
\hline & Group 2 & & 0,35 & 0,10 & 0,15 & 0,28 & 0,35 & 0,43 & 0,62 & & \\
\hline \multirow{4}{*}{ 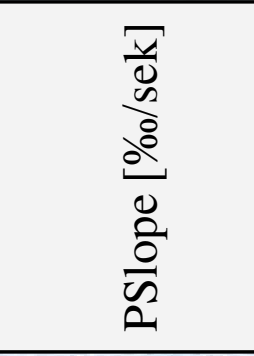 } & Group 1 & \multirow{2}{*}{ Before } & 5,74 & 1,31 & 2,25 & 4,45 & 5,80 & 6,65 & 6,75 & Group 1 & 0,3692 \\
\hline & Group 2 & & 4,13 & 1,30 & 1,95 & 3,25 & 4,45 & 4,80 & 5,25 & \multirow{3}{*}{ Group 2} & \multirow{3}{*}{0,4985} \\
\hline & Group 1 & $\Delta \mathrm{fter}$ & 5,77 & 1,33 & 3,65 & 4,75 & 5,90 & 6,65 & 7,25 & & \\
\hline & Group 2 & After & 4,26 & 1,33 & 2,25 & 3,65 & 4,40 & 4,80 & 6,85 & & \\
\hline \multirow{4}{*}{$\frac{\bar{g}}{\underline{\Xi}}$} & Group 1 & \multirow{2}{*}{ Before } & 169,27 & 16,41 & 141,00 & 160,00 & 164,50 & 173,00 & 198,00 & Group 1 & 0,8993 \\
\hline & Group 2 & & 164,20 & 6,92 & 152,00 & 156,00 & 165,50 & 169,00 & 171,00 & \multirow{3}{*}{ Group 2} & \multirow{3}{*}{0,0012} \\
\hline & Group 1 & 10 & 171,31 & 21,60 & 137,00 & 155,00 & 165,50 & 183,00 & 220,00 & & \\
\hline & Group 2 & After & 156,95 & 9,57 & 146,00 & 148,00 & 151,00 & 159,00 & 172,00 & & \\
\hline \multirow{4}{*}{$\begin{array}{l}\overline{\underline{g}} \\
\underline{\underline{\Xi}}\end{array}$} & Group 1 & \multirow{2}{*}{ Before } & 268,77 & 38,96 & 198,00 & 237,00 & 269,00 & 295,00 & 326,00 & Group 1 & 0,5649 \\
\hline & Group 2 & & 268,89 & 13,20 & 242,00 & 261,00 & 272,50 & 274,00 & 284,00 & \multirow{3}{*}{ Group 2} & \multirow{3}{*}{0,2234} \\
\hline & Group 1 & \multirow{2}{*}{ After } & 267,50 & 36,90 & 197,00 & 231,00 & 269,00 & 289,00 & 332,00 & & \\
\hline & Group 2 & & 267,33 & 22,94 & 230,00 & 257,00 & 264,00 & 267,00 & 306,00 & & \\
\hline
\end{tabular}

